\title{
Weak bond-linked components of the reserve and fibrillar cell walls of the endosperm of Gleditsia triacanthos (Leguminosae)
}

\author{
Cecilia I. Cappelletti, Diego A. Navarro, Adriana E. Manzi, Carlos A. Stortz, and Alberto \\ S. Cerezo* \\ Departamento de Química Orgánica-CIHIDECAR, Facultad de Ciencias Exactas y Naturales, \\ UBA. Ciudad Universitaria, Pab. 2, 1428 Buenos Aires, Argentina \\ E-mail: cerezo@qo.fcen.uba.ar
}

\section{Dedicated to Dr. R. M. Lederkremer on the occasion of her $70^{\text {th }}$ birthday}

\begin{abstract}
The whole system of low molecular weight/highly hydrophilic weak-bond linked components of the endosperm of the legume seed of Gleditsia triacanthos was studied on the basis of previous and new data. This reserve incrustant/fibrillar cell wall system may be considered a continuous phase formed by three types of compounds, namely: a) galactomannans/galactomannan-like oligosaccharides highly substituted (reserve) and with low branching (near mannans, fibrillar); b) "mixed-linkage"-glucans (reserve) and cellulose (fibrillar), and c) arabinans (reserve) and lowsubstituted arabinogalactans (fibrillar). The biological role of these "weak bond-linked" components is not fully understood but they may be multifunctional molecules, as they provide not only the weak bonds necessary for the swelling properties of the endosperm, but also they may contribute to the stabilization of enzymes in the dry endosperm by preventing dehydration.
\end{abstract}

Keywords: Legume seeds, endosperm, galactomannan, arabinan, glucan, arabinogalactan

\section{Introduction}

The swelling properties of the endosperm required to be constructed on the basis of a few strong bonds and many weak bonds. ${ }^{1}$ The first ones are formed between the galactomannan ribbon-like molecules reinforced through hydrogen bonding with a small amount of cellulose. ${ }^{1}$ Little is known about the "weak bond" components but the paramount amounts of low-molecular weight and/or highly hydrophilic components suggest that they play a major role in these formation. ${ }^{2}$ Components with these characteristics were extracted from the reserve material ${ }^{2}$ and fibrillar cell walls $^{3}$ of the endosperm of Gleditsia triacanthos in different conditions. This plant is a legume from the subfamily Caesalpinioidae, with albuminated seeds containing thick primary walls 
composed mainly of incrustant galactomannans. ${ }^{4}$ These galactomannans consist of a $\beta(1 \rightarrow 4)$ linked mannan backbone substituted with variable amounts of $(1 \rightarrow 6)-\alpha-D$-galactosyl side stubs. ${ }^{5}$

A whole characterization of the system of the $85 \%$ ethanol-soluble products from previous ${ }^{1-3}$ and new data is presented now together with an account of their interactions.

\section{Results and Discussion}

In a previous work, the endosperm of Gleditsia triacanthos was extracted exhaustively at room temperature, $50^{\circ} \mathrm{C}$ and $95{ }^{\circ} \mathrm{C}$. ${ }^{4}$ The galactomannans were precipitated with ethanol up to a concentration of $85 \%$, ${ }^{4}$ whereas the remaining $85 \%$ ethanol-soluble products were obtained from the supernatant. The same procedure was carried out with the fibrillar cell walls. ${ }^{3}$ In the first case, the sequential extractions produced the three samples $\mathbf{S}_{\mathbf{2 5}}, \mathbf{S}_{\mathbf{5 0}}$ and $\mathbf{S}_{\mathbf{9 5}}$. Partial studies about the former $\left(\mathbf{S}_{25}\right)$ and the latter $\left(\mathbf{S}_{95}\right)$ were previously reported, ${ }^{1,2}$ but herein is presented new material on them and studies on $\mathbf{S}_{\mathbf{5 0}}$. The material from the fibrillar cell wall yielded similar quantities of product by extraction with non-degrading, hydrogen bond-breaking (7M urea, SU), calcium-sequestering (1\% ammonium oxalate, SO), and alkali of different strengths (SK and SN). ${ }^{3}$ Yields, analysis and monosaccharide compositions of all the soluble products are given in Table 1. The analysis of the yields indicates that even if the major components of the endosperm are galactomannans of high molecular weight, substantial amounts (more than $25 \%$ ) of the endosperm weight is constituted by $85 \%$ ethanol-soluble products. These products are constituted by major amounts of galactose and mannose with occasionally larger quantities of glucose and arabinose in some cases and trace amounts of fucose and xylose. Protein is found in small amounts in all the fractions, as well as traces of $N$-acetyl-D-glucosamine.

Table $\mathbf{1}^{\mathrm{a}}$. Yields, ${ }^{\mathrm{b}}$ protein content and monosaccharide compositions of the $85 \%$ ethanol- soluble fractions and final residue $\mathrm{RN}$

\begin{tabular}{|c|c|c|c|c|c|c|c|c|c|}
\hline \multirow{2}{*}{ Fraction } & \multirow{2}{*}{$\begin{array}{c}\text { Yield }^{b} \\
(\%)\end{array}$} & \multirow{2}{*}{$\begin{array}{c}\text { Carbohyd. } \\
(\%)\end{array}$} & \multirow{2}{*}{$\begin{array}{c}\text { Protein } \\
(\%)\end{array}$} & \multicolumn{6}{|c|}{ Monosaccharide composition (mols/100 mols) } \\
\hline & & & & Fuc & Ara & Xyl & Man & Gal & Glc \\
\hline $\mathbf{S}_{25}$ & 5.1 & 80 & 7.5 & 1 & 6 & 2 & 39 & 26 & 25 \\
\hline $\mathrm{S}_{50}$ & 1.8 & 88 & 13.0 & - & 7 & - & 83 & 10 & tr. \\
\hline $\mathrm{S}_{95}$ & 2.3 & 62 & 26.0 & - & 60 & 3 & 22 & 15 & tr. \\
\hline $\mathbf{S U}^{\mathrm{c}}$ & $5.9^{\mathrm{c}}$ & ND & 2.5 & 7 & 12 & 4 & 44 & 21 & 12 \\
\hline $\mathbf{S O}^{\mathrm{c}}$ & $3.9^{\mathrm{c}}$ & ND & 4.5 & 2 & 4 & - & 43 & 21 & 29 \\
\hline $\mathbf{S K}^{\mathrm{c}}$ & 5.9 & ND & 16.0 & 3 & 5 & - & 76 & 5 & 11 \\
\hline $\mathbf{S N}^{\mathrm{c}}$ & 2.6 & ND & 0.3 & - & - & - & 92 & 5 & 2 \\
\hline $\mathbf{R} \mathbf{N}^{\mathrm{d}}$ & 0.8 & ND & ND & - & 6 & - & 39 & 6 & 46 \\
\hline
\end{tabular}

${ }^{\mathrm{a}}$ Most of the data has been previously reported. ${ }^{1-3}$ 
${ }^{b}$ Yields are given as percentages of the original endosperm. ${ }^{c}$ Large proportions of the extracts that yielded these products were lost by dialysis (molecular weight-cut off $=12,000$ ). ${ }^{\mathrm{d}}$ When hydrolyzed with $72 \%(\mathrm{w} / \mathrm{w})$ sulfuric acid, the amount of glucose increased to $63 \%$.

A galactomannan-oligosaccharide with an average degree of polymerization of 15 together with a water-soluble glucan and small amounts of arabinose-containing compounds were found in $\mathbf{S}_{25}{ }^{1}$. Some of the arabinose moieties appeared as non-reducing end-chain units in the galactomannan-like oligosaccharides but others could correspond to arabinans. ${ }^{1} \mathbf{S}_{50}$ was also composed by galactomannan- or mannan-like oligosaccharides of low DP and an arabinan. Gel permeation chromatography (on BioGel P-2 equilibrated with $0.2 \mathrm{M} \mathrm{NaCl}$ ) showed the presence of low molecular-weight galactomannan oligosaccharides with little substitution, as well as a higher molecular weight fraction that contains both the arabinan and the galactomannan components. This fraction $\left(\mathbf{S}_{\mathbf{5 0 - 1}}\right)$ was resubmitted to a new chromatography on the same gel, but equilibrated with water (Figure 1). This method allowed the separation into two subfractions $\left(\mathbf{S}_{50-1 \mathrm{~A}}\right.$ and $\left.\mathbf{S}_{\mathbf{5 0 - 1 B}}\right)$. No total separation was produced, as both fractions contain the three monosaccharides. However, $\mathbf{S}_{\mathbf{5 0 - 1 A}}$ is enriched in the arabinan constituent $(65 \%$ Ara, $26 \%$ Man, $9 \% \mathrm{Gal}$ ), whereas $\mathbf{S}_{50-1 \mathrm{~B}}$ is almost devoid of that component (8\% Ara, 74\% Man, 18\% Gal).

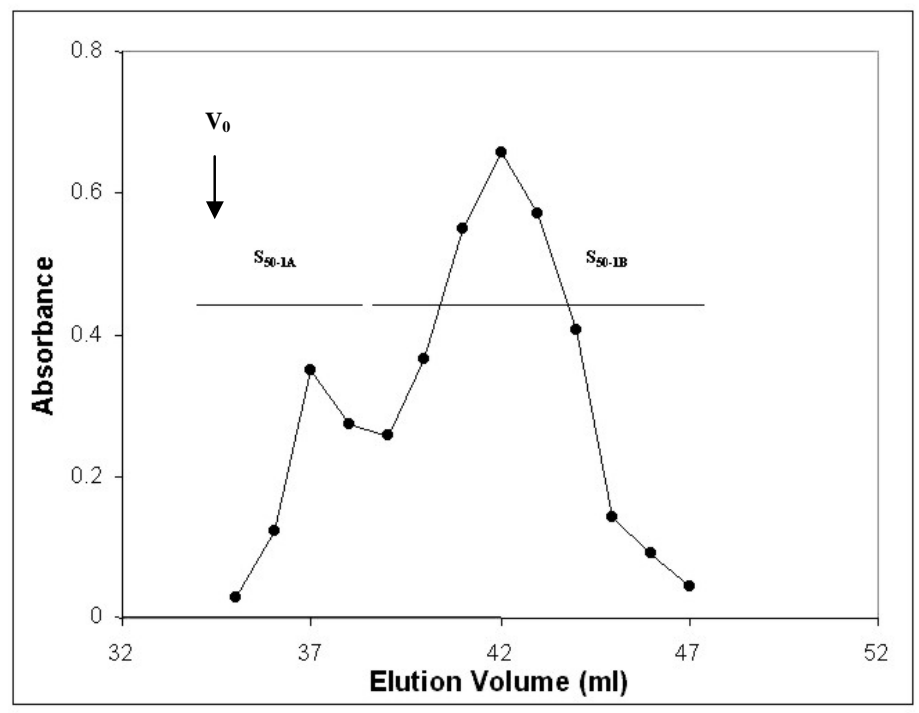

Figure 1. Elution pattern of the rechromatography of fraction $\mathbf{S}_{50-1}$ on a column of Bio-Gel P2 $(1.2 \times 30 \mathrm{~cm})$, eluted with water. Absorbance was determined at $490 \mathrm{~nm}\left(\mathrm{PhOH} / \mathrm{H}_{2} \mathrm{SO}_{4}\right.$ method).

$\mathbf{S}_{95}$ was constituted by two different galactomannan oligosaccharides, accompanied of a $\beta$ $(1 \rightarrow 4)$ galactan and major amounts of an arabinan. ${ }^{2}$ The arabinans from $\mathbf{S}_{\mathbf{5 0}}$ and $\mathbf{S}_{\mathbf{9 5}}$ show very similar ${ }^{13} \mathrm{C}$-NMR spectra (Figure 2), indicative of a 5-linked arabinan main chain, branched mainly on $\mathrm{C} 2$ and less on $\mathrm{C} 3$. $^{2}$ 
Table 1 shows that all the extracts contain variable proportions of protein. The amino acid composition of the proteic moieties of the three $85 \%$ ethanol-soluble products obtained after water extraction is shown in Table 2. The amino acid composition of $\mathbf{S}_{\mathbf{2 5}}$ differs from those of the co-extracted galactomannans ${ }^{4}$ by the presence of higher amounts of aspartic acid/asparagine and histidine and lower quantities of serine. $\mathbf{S}_{\mathbf{5 0}}$ shows higher amounts of glutamic acid/glutamine and lesser of lysine, alanine and especially serine than those of its galactomannans. ${ }^{4}$ In $\mathbf{S}_{95}$ there are, again, more glutamic acid/glutamine and threonine with lower amounts of aspartic acid/asparagine, arginine, and histidine. When comparing the amino acid compositions of $\mathbf{S}_{25}$, $\mathbf{S}_{50}$ and $\mathbf{S}_{95}$ with those of the corresponding $85 \%$ ethanol-soluble components of the fibrillar cell wall proteins, it is observed that the resemblance, especially considering the proportions of Asp/Asn and Thr, travels in the same direction from $\mathbf{S}_{25}$ to $\mathbf{S}_{\mathbf{9 5}}$ as from $\mathbf{S U}$ to $\mathbf{S O}$ to $\mathbf{S K}^{3}$ in agreement with the difficulty of the extraction procedure.
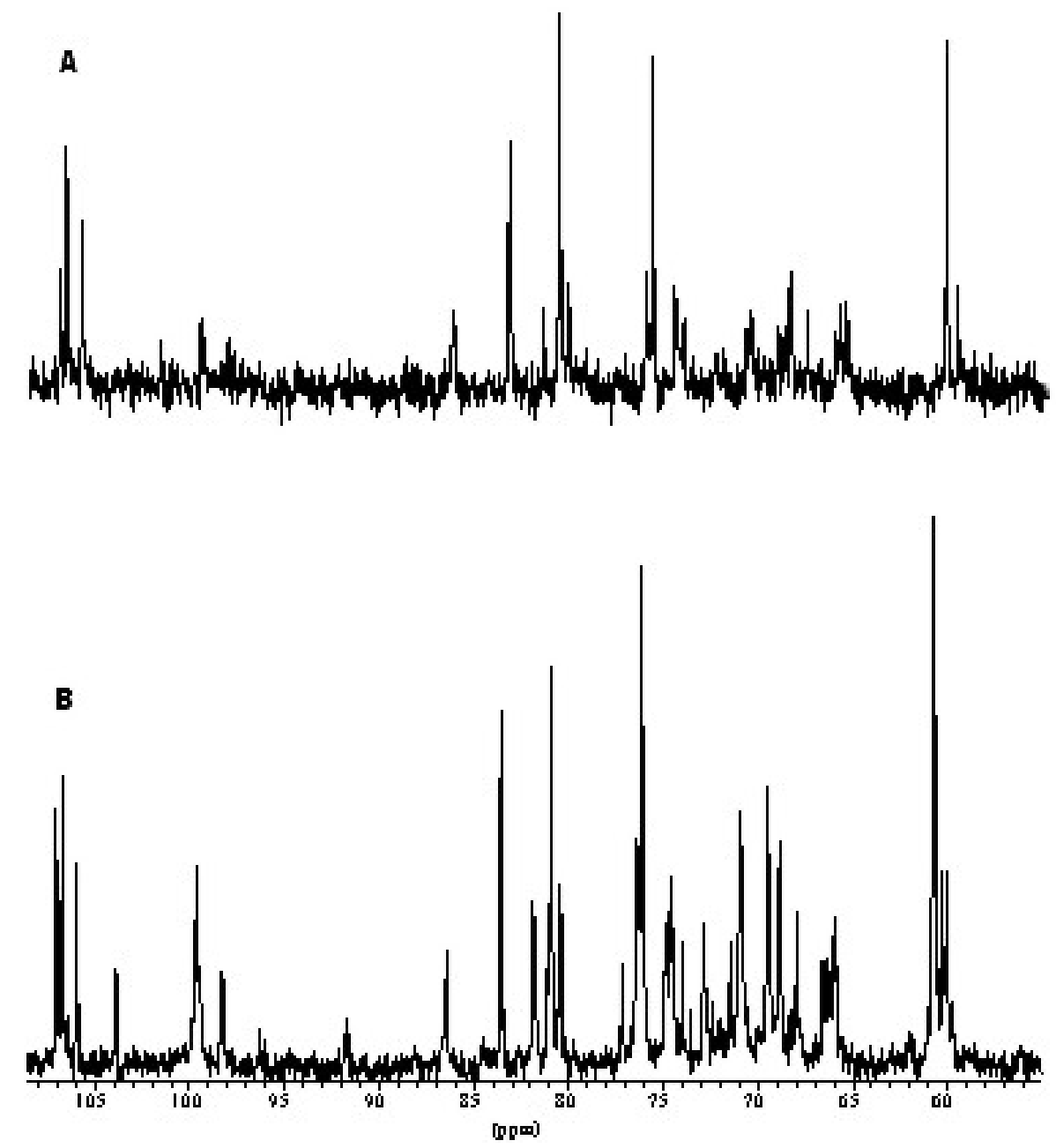

Figure 2. $125 \mathrm{MHz}$ proton-decoupled ${ }^{13} \mathrm{C}$ NMR spectra of fractions $\mathbf{S}_{\mathbf{5 0 - 1 A}}(\mathrm{a})$ and $\mathbf{N}_{\mathbf{9 5}}(\mathrm{b})$. 
Table 2. Amino acid composition of the water-extractable, $85 \%$ ethanol-soluble products from the endosperm of the seed of Gleditsia triacanthos

\begin{tabular}{lcccccccccccccccc}
\hline \multicolumn{1}{l}{ Fraction } & \multicolumn{11}{c}{ Amino acid } \\
& Asp & Thr & Ser & Glu & Pro & Gly & Ala & Val & Met & Ile & Leu & Tyr & Phe & Lys & His & Arg \\
\hline $\mathbf{S}_{\mathbf{2 5}}$ & 20 & 4 & 6 & 14 & 4 & 6 & 8 & 5 & 0 & 3 & 6 & 5 & 3 & 8 & 8 & 0 \\
$\mathbf{S}_{\mathbf{5 0}}$ & 12 & 4 & 4 & 26 & 4 & 4 & 5 & 5 & 1 & 4 & 8 & 7 & 5 & 3 & 4 & 4 \\
$\mathbf{S}_{\mathbf{9 5}}$ & 5 & 10 & 6 & 22 & 4 & 7 & 7 & 5 & 3 & 6 & 8 & 3 & 3 & 4 & 2 & 5 \\
\hline
\end{tabular}

aThe amino acid composition is expressed in grams per $16 \mathrm{~g}$ of N. Percentages lower than $0.5 \%$ have not been considered.

The $85 \%$-soluble products extracted from the fibrillar cell wall were mainly composed of galactomannan oligosaccharides with high Man/Gal ratio together with short chains of cellulose, and small amounts of arabinans and/or arabinogalactans. ${ }^{3}$ Neither of the $\mathbf{S}$ fractions contained uronic acids. Analysis of cations in $\mathbf{S}_{\mathbf{9 5}}$ indicates that the components retained salts of calcium and magnesium in, approximately, $0.15 \% \mathrm{w} / \mathrm{w}$ in spite of having no acidic groups in the carbohydrate moieties.

Table 1 shows the presence of glucose in many of the fractions, suggesting the existence of different kinds of glucans, namely: a) one extracted with water at room temperature (in $\mathbf{S}_{25}$ ); b) one extracted with chaotropic and/or alkaline solvents (in SU, SO and SK), and c) one nonextractable in any conditions (in $\mathbf{R N}$ ). The first glucan is, according to its solubility in water, methylation analysis (see later) and gel permeation chromatography (Sephadex G 200 using 7M urea as solvent ${ }^{1}$ ) a mixed-linkage $\beta-(1 \rightarrow 4) /(1 \rightarrow 3)$ low-molecular weight glucan. The third glucan is high-molecular weight fibrillar cellulose, whereas the second one corresponds to, possibly, low-molecular weight cellulose chains. A solubilization of cellulose from xyloglucan short segments (SU) by complexation and/or encapsulation by other polysaccharides have been previously observed. ${ }^{6}$ It has been proposed that these units represent part of the reserve or the fibrillar cell wall which, due to functional reasons, were packed without the usual cohesion forces existing in the microfibrils. ${ }^{6}$

The fractions from the aqueous extracts $\left(\mathbf{S}_{25}, \mathbf{S}_{\mathbf{5 0}}\right.$ and $\left.\mathbf{S}_{\mathbf{9 5}}\right)$ were fractionated by anionexchange chromatography giving a "neutral" subfraction eluted with water (N) and "charged" subfractions eluted with ammonium carbonate $(\mathbf{C}),{ }^{1,2}$ as shown in Figure 3. Different ionexchange chromatographies many times fail to reproduce either the recoveries or the composition of the fractions. This lack of reproducibility has been previously noted in the fractionation of galactomannans and appears to be associated with temperature-, time-, and composition dependent associations between the components and between the components and the anion-exchanger. ${ }^{1}$ Yields and compositions are given in Table 3 . The yields of the $\mathbf{N}$ fractions are larger than those of the $\mathbf{C}$ fractions for the room-temperature extraction, and very similar for the remaining ones. Anyway, the fractionation was probably not due to the presence of charged groups in the $\mathbf{C}$ subfractions, as carboxyl and/or sulfate groups were not found in the 
carbohydrate while the composition of the protein was similar in both subfractions, but to nonbonded interactions between the polysaccharide components of the $\mathbf{C}$ fractions and the Sephadex DEAE-50 of the column.
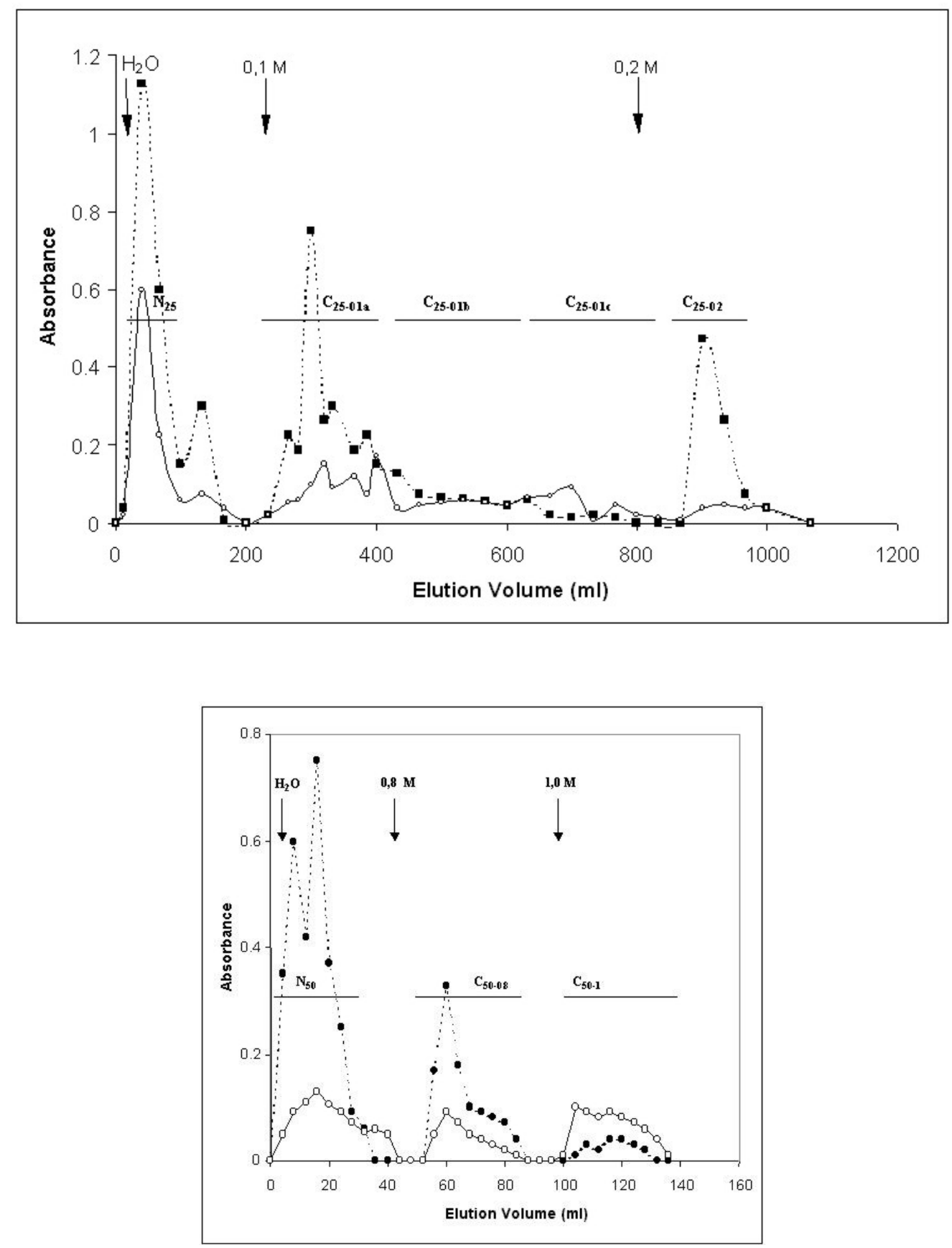

Figure 3. Elution pattern on DEAE-Sephadex A-50 of fractions $\mathbf{S}_{25}$ (upper, column $2.5 \times 30 \mathrm{~cm}$ ) and $\mathbf{S}_{50}$ (lower, column $1.9 \times 10 \mathrm{~cm}$ ). The columns were washed with water and then eluted with ammonium carbonate solutions of the concentrations indicated. Key (-) $\mathrm{A}_{280 \mathrm{~nm}},(---) \mathrm{A}_{490 \mathrm{~nm}}$. 
Table 3. Yields and composition of the subfractions obtained by anion-exchange chromatography of the fractions soluble in $85 \%$ ethanol

\begin{tabular}{|c|c|c|c|c|c|c|c|c|c|}
\hline \multirow{2}{*}{ Fraction ${ }^{\mathrm{a}}$} & \multirow{2}{*}{ Yield $^{b}(\%)$} & \multicolumn{6}{|c|}{ Monosaccharide (mols/100 mols) } & \multirow{2}{*}{$\begin{array}{c}\text { Protein } \\
(\%)\end{array}$} & \multirow{2}{*}{$\begin{array}{c}\text { Man/Gal } \\
\text { ratio }\end{array}$} \\
\hline & & Fuc & Ara & Xyl & Man & Gal & Glc & & \\
\hline $\mathbf{N}_{25}$ & $52(2.50)$ & $\operatorname{tr}^{\mathrm{c}}$ & 2 & - & 68 & 30 & $\operatorname{tr}$ & 3 & 2.26 \\
\hline $\mathbf{N}_{50}$ & $35(2.70)$ & 3 & 5 & - & 57 & 33 & 2 & 7 & 1.77 \\
\hline $\mathbf{N}_{95}$ & $42(0.34)$ & 2 & 38 & 2 & 37 & 16 & 5 & 5 & 2.24 \\
\hline $\mathbf{N}_{95}{ }^{d}$ & $23(0.53)$ & - & 48 & 1 & 37 & 14 & $\operatorname{tr}$ & 11 & 2.64 \\
\hline $\mathrm{C}_{25-0.1 \mathrm{a}}$ & $5.3(0.20)$ & 2 & 7 & 16 & 24 & 42 & 8 & 10 & 0.56 \\
\hline $\mathrm{C}_{25-0.1 \mathrm{~b}}$ & $1.2(0.05)$ & 5 & 12 & 9 & 17 & 46 & 11 & n.d & 0.30 \\
\hline $\mathrm{C}_{25-0.1 \mathrm{c}}$ & $0.5(0.02)$ & 9 & 17 & 7 & 13 & 45 & 10 & n.d & 0.28 \\
\hline $\mathrm{C}_{25-0.2}$ & $1.6(0.06)$ & 6 & 20 & 5 & 9 & 51 & 9 & n.d & 0.18 \\
\hline $\mathrm{C}_{50-0.8}$ & $49(3.70)$ & 5 & 15 & 11 & 22 & 44 & 3 & 2 & 0.50 \\
\hline$C_{50-1.0}$ & $15(1.20)$ & 5 & 16 & 10 & 22 & 44 & 4 & 7 & 0.50 \\
\hline $\mathrm{C}_{95}^{\mathrm{d}}$ & $50(1.15)$ & - & 67 & 5 & 14 & 14 & - & 20 & 1.00 \\
\hline $\mathrm{C}_{95-0.8}$ & $50(0.40)$ & 12 & 65 & 9 & 3 & 11 & - & 4 & 0.26 \\
\hline $\mathrm{C}_{95-1.0}$ & $3.6(0.03)$ & 12 & 66 & 9 & 3 & 11 & - & 6 & 0.26 \\
\hline
\end{tabular}

aFor nomenclature see text. bThe yield is expressed in percent of the previous product. In parentheses, the yield respect to the original endosperm is indicated. ${ }^{c} \operatorname{tr}=\operatorname{traces} .{ }^{\mathrm{d}}$ Corresponds to another batch, precipitated with $75 \%$ isopropanol. $^{2}$

It is noteworthy that the Man/Gal ratio in the $\mathbf{N}$ subfractions is always higher than $1(1.8-$ 2.3), as expected in terms of galactomannan-like oligosaccharides, whereas in the $\mathbf{C}$ subfractions, this ratio is usually lower than 1 indicating that those galactomannans should be accompanied by a galactan. Previous studies on the $\mathbf{N}_{\mathbf{9 5}}$ and $\mathbf{C}_{\mathbf{9 5}}$ indicated precisely the presence of a 4-linked $\beta$ D-galactan core of an arabinogalactan of type I. ${ }^{2}$

The extract obtained with 7M urea (SU, Table 1) still contained some arabinose but those obtained with oxalate (SO) or alkali (SK and SN) showed little proportion of this sugar indicating that the arabinose-containing compounds are located mainly in the reserve tissue and not in the fibrillar cell wall. However, small amounts of this sugar appear in the final residue (RN), suggesting that the cell wall is built up not only by major amounts of cellulose and fibrous galactomannans, but also by minor amounts of modified hydrophilic compounds similar to those found in the reserve tissues.

It is noteworthy the changes in optical rotation of these fractions in passing from plain water to solutions with high ionic strength or hydrogen bond-breaking (Table 4) suggesting the association of its components. GPC of fractions $\mathbf{S}_{25}$ and $\mathbf{S}_{\mathbf{5 0}}$ show that they fail to fractionate, in agreement with the association properties of these products (Figure 4). The behavior is clearly different in water and in 7M urea (Figure 5). 
Methylation of $\mathbf{N}_{\mathbf{2 5}}, \mathbf{N}_{\mathbf{5 0}}$ and $\mathbf{N}_{\mathbf{9 5}}$ was attempted using a two-step procedure (Table 5). The methylation pattern is similar in both steps for $\mathbf{N}_{25}$, compatible with the structure of a galactomannan and indicating a complete methylation.
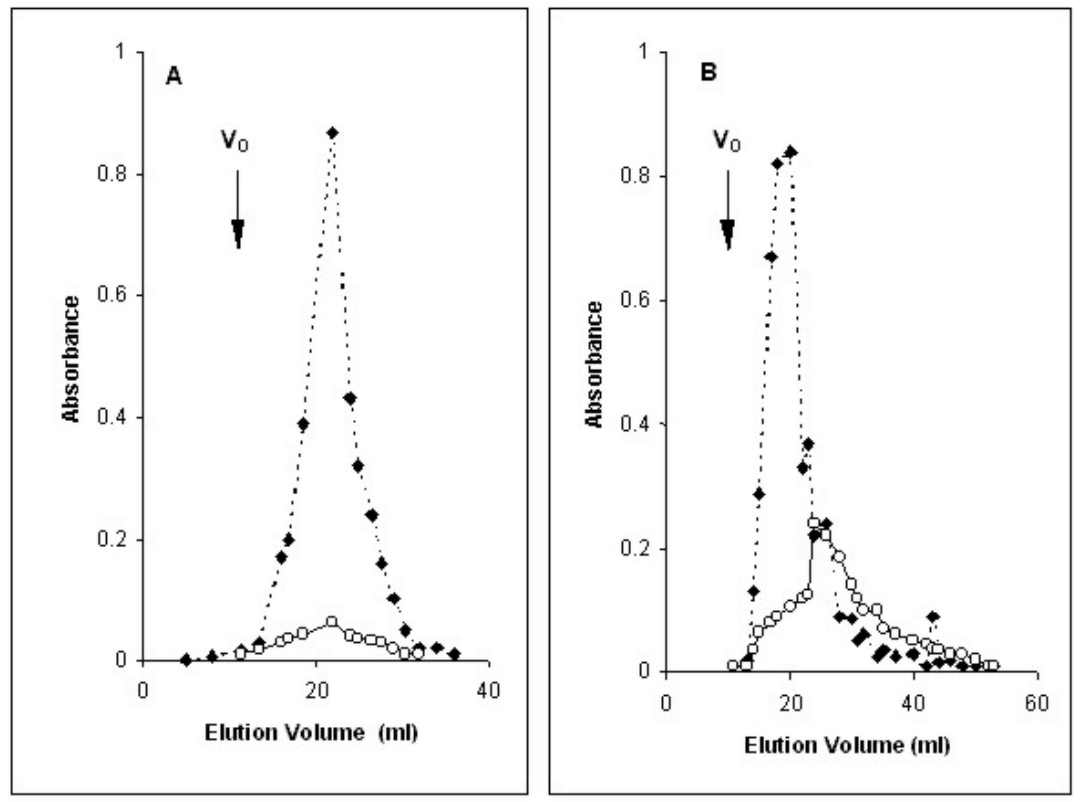

Figure 4. Elution pattern on an analytical column $(1.2 \times 60 \mathrm{~cm})$ of Sephadex $\mathrm{G}-15$ eluted with water of fractions $\mathbf{S}_{25}(\mathrm{~A})$ and $\mathbf{S}_{50-1}(B)$. Key (-) $\mathrm{A}_{280 \mathrm{~nm}},(--) \mathrm{A}_{490 \mathrm{~nm}}$.
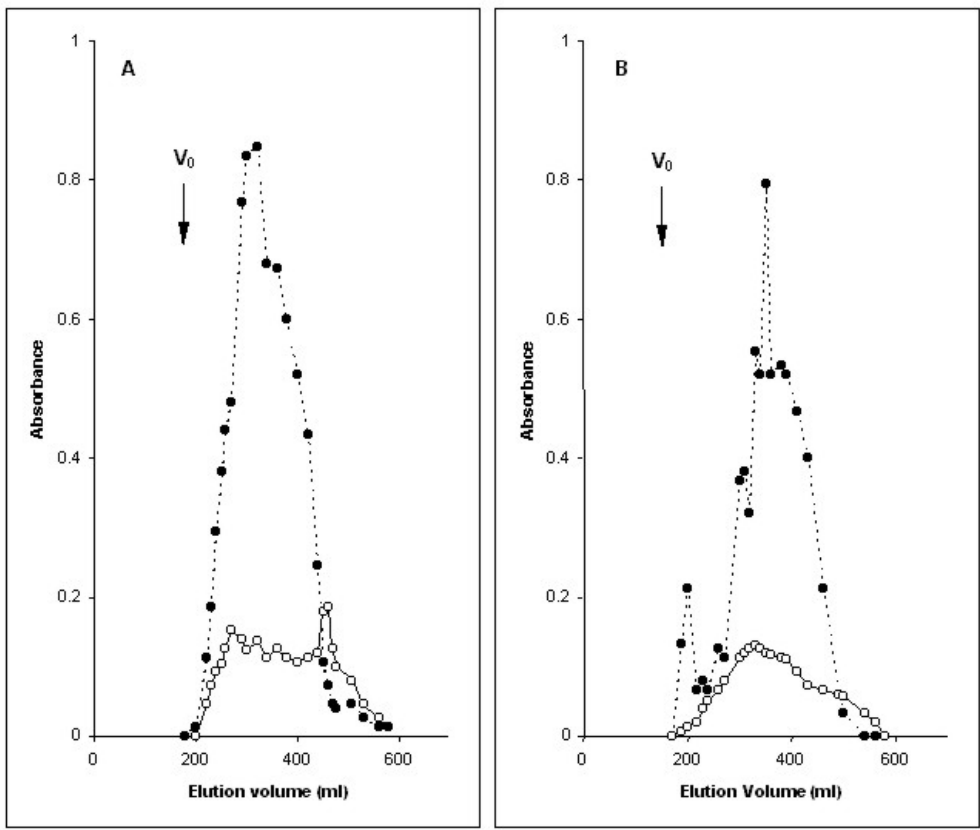

Figure 5. Elution pattern on a preparative column $(3.5 \times 80 \mathrm{~cm})$ of Sephadex G-100, of fraction $\mathbf{S}_{25}$ eluted with water (A) and 7M urea (B). Key (-) $\mathrm{A}_{280 \mathrm{~nm}},(---) \mathrm{A}_{490 \mathrm{~nm}}$. 
Table 4. Optical rotations of the fractions in different solvents

\begin{tabular}{ccccc}
\hline Fraction $^{\mathrm{a}}$ & $\begin{array}{c}\text { Man/Gal } \\
\text { ratio }\end{array}$ & Water & $\begin{array}{c}{[\alpha]_{\mathrm{D}}} \\
0.1 \mathrm{M} \mathrm{NaCl}\end{array}$ & $7 \mathrm{M}$ Urea \\
\hline $\mathbf{S}_{\mathbf{2 5}}$ & 1.55 & +51.0 & +32.3 & +46.4 \\
$\mathbf{S}_{\mathbf{5 0}}$ & 2.85 & +30.2 & +12.4 & +5.2 \\
$\mathbf{S}_{\mathbf{9 5}}$ & 1.68 & -4.5 & -5.0 & -25.8 \\
$\mathbf{S U}$ & 2.00 & +9.6 & +8.7 & -18.0 \\
$\mathbf{S O}$ & 2.00 & +60.7 & +17.5 & -0.6 \\
$\mathbf{P K}$ & 4.40 & +7.5 & +0.1 & -29.0 \\
$\mathbf{S K}$ & 16.90 & -19.0 & -7.4 & -15.5 \\
$\mathbf{E S}$ & 17.40 & -5.2 & -4.2 & -18.0 \\
\hline
\end{tabular}

Table 5. Methylation analysis of the "neutral fractions" extracted at different temperatures $\mathrm{a}^{\mathrm{a}}$

\begin{tabular}{ccccccc}
\hline \multirow{2}{*}{ Monosaccharide } & \multicolumn{2}{c}{$\mathbf{N}_{\mathbf{2 5}}$} & \multicolumn{2}{c}{$\mathbf{N}_{\mathbf{5 0}}$} & \multicolumn{2}{c}{$\mathbf{N}_{\mathbf{9 5}}$} \\
\cline { 2 - 7 } & $1^{\text {st }}$ step $^{\text {c }}$ & $2^{\text {nd }}$ step $^{\text {d }}$ & $1^{\text {st }}$ step & $2^{\text {nd }}$ step & $1^{\text {st }}$ step & $2^{\text {nd }}$ step \\
\hline 2,3,4,6-Man & 6 & 7 & - & - & - & - \\
2,3,6-Man & 41 & 37 & 32 & 30 & 30 & 42 \\
2,3-Man & 23 & 21 & 35 & 40 & 25 & 33 \\
Man & - & - & 13 & 10 & 7 & 5 \\
2,3,4,6-Gal & 24 & 27 & 5 & 1 & 6 & 2 \\
2,3,6-Gal & 2 & 7 & - & - & - & - \\
2,4-Gal & 4 & 7 & - & - & 27 & 10 \\
Gal & - & - & 15 & 19 & 5 & 8 \\
\hline
\end{tabular}

"The comparision is centered on the "galactomannan" part of $\mathbf{N}$, considered as $100 \%$ as $\mathbf{N}_{95}$ contained considerable amounts of arabinose (see Table 3). The fractions correspond to the batch precipitated with $85 \%$ ethanol (see Table 3). b2,3,4,6-Man = 2,3,4,6-tetra- $O$-methylmannose, etc. ${ }^{\mathrm{c}}$ Methylated by Hakomori method. ${ }^{\mathrm{d}}$ Methylated by Haworth and Hakomori sequences.

On the other hand, in $\mathbf{N}_{\mathbf{5 0}}$ and $\mathbf{N}_{\mathbf{9 5}}$, part of the molecules have their hydroxyl groups blocked, and thus they are not accesible either to the ionizing or to the methylating reagent. Methylation of of several of the "charged" fractions obtained from fraction $\mathbf{S}_{25}$ after ion-exchange chromatography. Submethylation is observed in all the fractions in spite of the solubility of the products in dimethyl sulfoxide and of the harsh conditions employed. Even if no structural data can be obtained from these results (not shown), the high percentages of terminal units suggest the presence of highly branched products.

Weak multivalent interactions play an important role in biological systems. ${ }^{7}$ Whereas many examples are known of protein-protein and protein-carbohydrate interactions few studies exist about carbohydrate-carbohydrate interactions. ${ }^{8}$ 
The endosperm of legume seeds consists of a parenchymatic tissue of branched cells with thick primary walls containing major amounts of carbohydrates as incrustants together with minor amounts of proteins. ${ }^{9}$ The incrustants are mainly constituted by galactomannans formed

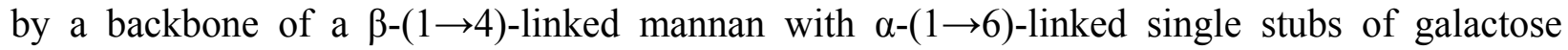
together with galactomannan-like oligosaccharides, small amounts of highly branched arabinans and traces of a $(1 \rightarrow 4),(1 \rightarrow 3)$-“mixed linkage" glucan and a $\beta-(1 \rightarrow 4)$ - galactan.

The family of galactomannans, which differ in the Man/Gal ratio and in the arrangement of the stubs, produced solutions of high viscosity or gels when complexed with other polysaccharides, having widespread uses in different industries and high commercial value, ${ }^{10}$ and have been thoroughly studied. However, little is known about the remaining components. The endosperm functions as a reservoir in dry state to feed the embryo after the germination of the seed. To accomplish this function, it packs tightly the reserve products until needed. ${ }^{11}$ Then, hydration swells the tissue and allows the glycosidases from the aleurone to hydrolyze the galactomannans into low-molecular weight carbohydrates that feed the embryo. These packing and swelling properties of the endosperm require the reserve and cell walls to be constructed on the basis of a few strong bonds and many weak ones. ${ }^{1}$ The strong bonds are built up through the complexation of galactomannan ribbon-like molecules reinforced by hydrogen bonding with a small amount of cellulose fibrils. These interactions have been found in the binding of mannan and dextran, ${ }^{12}$ xyloglucan and cellulose,${ }^{13}$ and models containing multiple nitrogen and oxygen donors and acceptors. ${ }^{14}$ Little is known about the weak bonds and of the components that contribute to its formation.

In order to obtain a wider view of the chemical composition and interactions between the components of the whole system of reserve and fibrillar cell wall, the low-molecular weight and hydrophilic components soluble in $85 \%$ ethanol previously and herein studied have been taken into consideration.

The reserve and fibrillar cell walls contain not only the major high-molecular weight galactomannans but also significant quantities of galactomannan-like oligosaccharides with different DP. These relations between high- and low-molecular weight materials of the same structural type in the amorphous and the fibrous phase of the cell walls have also been observed in red seaweeds. ${ }^{15}$ Galactans with low molecular weights and structures similar to those of the high molecular weight matricial galactans were found in red algae. It was thought that the smaller ones were precursors or degradation products of the larger counterparts and that its complexation with the higher galactans could be used to reversibly modulate its gelification. ${ }^{16}$ The latent endosperm is a place with little or no biological activity and the oligosaccharides could be a remnant of the synthesis of the galactomannans but not the result of its degradation. Small-to-trace amounts of compounds structurally unrelated to the major ones were found in the cell wall of the red seaweed Kappaphycus alvarezii ${ }^{17}$ and in the endosperm. Thus, the reserve/fibrillar cell wall of the endosperm could contain a system of polysaccharides formally similar to that of the matrix/fibrillar cell wall of red seaweeds. 
The galactomannan oligosaccharides exist in aqueous solution in ordered conformations (Table 4) producing aggregates, but these aggregates differ from its high-molecular counterparts ${ }^{4}$ because they dissociate in $7 \mathrm{M}$ urea. This easier dissociation can be ascribed to a shorter backbone with concomitant decrease of cooperative interactions. Nevertheless, the interactions between these oligosaccharides and the "non-galactomannan" components of the "soluble" products still exist in urea 7M. Strong interactions, or covalent linkages, must exist between the oligosaccharides and the non-galactomannan components as no attempt of fractionation in highly polar (Figure 4) or hydrogen bond-breaking media (Figure 5) was successful in obtaining fractions or subfractions with a monosaccharide composition corresponding to the single compounds (Tables 1 and 3).

Arabinans have been found in primary cell walls of different parts of plants of many families. ${ }^{18}$ Various degrees of branching are possible, a linear $(1 \rightarrow 5)$ arabinan has been found in apple juice, ${ }^{19}$ and in the seed coat of several legume seeds ${ }^{20,21}$ while an almost linear one was found in the hypocotyl cells of Vigna radiata. ${ }^{22}$ In the arabinan from Althaea officinalis large amounts of branches on $\mathrm{C} 2$ and $\mathrm{C} 3$ have been found. ${ }^{23}$ Methylation analysis and ${ }^{13} \mathrm{C}-\mathrm{NMR}$ spectral analysis of $\mathbf{C}_{95}$ and $\mathbf{N}_{95}$ show that the arabinan of $G$. triacanthos follows the usual $(1 \rightarrow 5)$ backbone of $\alpha$-L-arabinofuranoses partially branched on $\mathrm{C} 2$ and in much lower amount on $\mathrm{C} 3{ }^{2}$

The presence of 4-linked galactopyranose units in small amounts was previously assigned to double stubs in the galactomannan molecules. ${ }^{1,4}$ However, NMR data show that this unit is more compatible with a $(1 \rightarrow 4)-\beta$-D-galactan core of an arabinogalactan of type I with a few, undetectable, arabinan substitutions similar to the homogalactans encountered in the mature hypocotyl cells of Vigna radiata ${ }^{22}$, Lupinus albus ${ }^{24}$, Solanum tuberosum ${ }^{25}$ and other sources. In those examples, the galactans also appeared associated with arabinans or other pectic substances. ${ }^{26}$

The "mixed linkage" $\beta$-D-glucans are unbranched homopolymers of glucose containing a mixture of $(1 \rightarrow 4)-\beta$-D-glucose linear sequences and $(1 \rightarrow 3)-\beta$-D-glucose "kinks". They are typical of primary cell walls (type II cell walls) of the Poaceae. ${ }^{27}$ During cell elongation, the glucan molecule may be the interlocking polysaccharide of the microfibrils of the type II cell walls. ${ }^{27}$ It is possible that they play a similar role in the reserve material of the endosperm. It is known that in the cell walls of the Poaceae 5-linked arabinans are found in the walls of the dividing cells, but are no longer produced during cell expansion. Instead, the "mixed linkage" glucans are synthesized in that stage. ${ }^{27}$

Thus, this reserve incrustant/fibrillar cell wall system may be considered as a continuous phase formed by three types of compounds: a) galactomannans/galactomannan-like oligosaccharides highly substituted (reserve material) and "near mannans" with very low substitution (fibrillar material), b) "mixed linkage"-glucans (reserve material) and cellulose (fibrillar material) and c) arabinans (reserve material) and arabinogalactans of low substitution (fibrillar material). The galactomannans have been proposed to be multifunctional molecules playing a role in the water uptake by the seed during germination and serving as reserve 
compounds during seedling development. ${ }^{11}$ The biological role of these "weak bond-linked" components is not completely understood. They cannot only contribute to the formation of the weak bonds needed for the swelling properties of the endosperm, but also they may contribute to stabilize the enzymes in the dry endosperm by preventing dehydration. ${ }^{11}$

\section{Experimental Section}

Plant material. The seeds of Gleditsia triacanthos were collected from ripe pods at Buenos Aires (Argentina). The separation of the endosperm from the embryo and testa was carried out by hand, after swelling the seeds by soaking them in boiling water for $10 \mathrm{~min}$, as reported earlier. ${ }^{4}$ Negligible solubilization of material occurred. ${ }^{4}$

Extraction and fractionation. The endosperm was extracted, as already described. ${ }^{1-3}$ First it was exhaustively extracted with water at room temperature. The galactomannans in the combined extracts were precipitated by stepwise addition of ethanol up to an $85 \%$ concentration, aided by mechanical stirring. The ethanol-soluble product $\left(\mathbf{S}_{25}\right)$ was obtained by concentration and lyophilization of the solutions. The residue of the extraction was extracted exhaustively with water at $50^{\circ} \mathrm{C}$, and then at $95^{\circ} \mathrm{C}$, yielding in a similar fashion the products $\mathbf{S}_{\mathbf{5 0}}$ and $\mathbf{S}_{\mathbf{9 5}}$ was obtained after precipitation of the galactomannans with isopropanol up to a concentration of $75 \%$, removal of the isopropanol from the supernatant in a rotatory evaporator, and final freezedrying. Anion-exchange chromatography was carried out using DEAE-Sephadex A-50 (carbonate form, $2.5 \times 30 \mathrm{~cm}$ ) equilibrated with water. Elution was first achieved with water, giving rise to the $\mathbf{N}$ fractions, and then with solutions of ammonium carbonate of increasing concentration, giving rise to several $\mathbf{C}$ fractions (see Results). The $\mathbf{C}$ fractions were isolated by repeated evaporation (in order to desalt), and lyophilization. Several gel-permeation chromatography runs were carried out, in the conditions indicated in the epigraph of the corresponding Figures (1 and 3-5).

The fractions SU, SO, SK and SN were obtained as already described. ${ }^{3}$ The residue remaining after aqueous extractions was exhaustively extracted with $7 \mathrm{M}$ urea at room temperature for $8 \mathrm{~h}$. The $85 \%$ ethanol-soluble products were recovered by freeze-drying (SU). The residue was extracted with boiling 1\% ammonium oxalate solution for $2 \mathrm{~h}$. The $85 \%$ ethanol-soluble products were recovered (SO). The residue was re-extracted with $10 \% \mathrm{KOH}$ solution at room temperature and the extract was dialyzed up to neutrality. Then an $85 \%$ ethanol-soluble product was recovered (SK). The final residue was extracted with $25 \%$ sodium hydroxide containing $5 \%$ sodium borate. An $85 \%$ ethanol-soluble product was recovered (SN).

Analytical methods. Total carbohydrates were assayed by the phenol-sulfuric acid method. ${ }^{28}$ Protein was quantitated by the method of Lowry et al., ${ }^{29}$ using bovine serum albumin as standard. Molecular weights were calculated from the reducing power, which was determined by the method of Park and Johnson. ${ }^{30}$ Uronic acids were determined by the method of Filizetti- 
Cozzi and Carpita, ${ }^{31}$ using glucuronolactone as standard. The proportions of monosaccharides constituting the polysaccharides were determined by gas chromatography (GLC) of the hydrolyzates $\left(2 \mathrm{M} \mathrm{CF}_{3} \mathrm{COOH}, 90 \mathrm{~min}, 120{ }^{\circ} \mathrm{C}\right)$, using alditol or aldononitrile acetates. These derivatives were analyzed by GLC using a capillary column (30 m x $0.25 \mathrm{~mm})$ coated with SP$2330(0.20 \mu \mathrm{m})$, using nitrogen as the carrier with a flow rate of $1 \mathrm{~mL} / \mathrm{min}$, in the split mode (split ratio 1:100). Runs were carried out isothermally at $220{ }^{\circ} \mathrm{C}$. Injector and detector (FID) were kept at $230{ }^{\circ} \mathrm{C}$. Optical rotations at equilibrium were measured at room temp using 0.7$1.0 \%$ solutions of the samples in water, $0.1 \mathrm{M} \mathrm{NaCl}$ and $7 \mathrm{M}$ urea, as indicated.

Cation analysis. It was carried out by atomic absorption spectroscopy of the samples in water solutions on a Shimadzu 6800 instrument equipped with an auto sampler. Commercial standards (Merck) were used for calibration.

Amino acid analyses. They were performed using a Technicon Sequential Multi-Sample Amino Acid analyzer, following hydrolysis of the protein with $6 \mathrm{~N} \mathrm{HCl}$ at $105^{\circ} \mathrm{C}$ for $24 \mathrm{~h}$. The mixture of amino acids was purified by absorption on Amberlite IR-120 $\left(\mathrm{H}^{+}\right)$

13C-NMR Spectroscopy. The spectra were obtained on a Bruker AM-500 spectrometer provided with a $5 \mathrm{~mm}$ probe, at room temperature. The samples were dissolved in $\mathrm{D}_{2} \mathrm{O} / \mathrm{H}_{2} \mathrm{O}$ 1:1. Acetone was used as internal standard, and chemical shifts were referred to TMS by calibrating the methyl acetone peak as $31.1 \mathrm{ppm}$.

Methylation analysis. Methylation was carried out on purified fractions by the method of Hakomori, as described previously. ${ }^{32}$ When complete methylation was not feasible with this procedure, the partially methylated polysaccharide was isolated, and submitted to a Haworth methylation followed once more by a Hakomori ${ }^{32}$ methylation step. The permethylated polysaccharide was isolated by dialysis, hydrolyzed (45\% formic acid, $\left.16 \mathrm{~h}, 100{ }^{\circ} \mathrm{C}\right)$, and their alditol acetates were analyzed by GC-MS.

\section{Acknowledgements}

This work was supported by grants of CONICET and UBA. C. A. S. and A. S. C. are Research Members of the National Research Council of Argentina (CONICET).

\section{References and Footnotes}

1. Manzi, A.E.; Cerezo, A. S. Carbohydr. Res. 1984, 134, 115.

2. Navarro, D. A.; Cerezo, A. S. ; Stortz, C. A. Carbohydr. Res. 2002, 337, 255.

3. Manzi, A. E.; Ancibor, E.; Cerezo, A. S. Plant Physiol. 1990, 92, 931.

4. Manzi, A.E.; Mazzini, M. N.; Cerezo, A. S. Carbohydr. Res. 1984, 125, 127.

5. Dea, I. C. M.; Morrison, A. Adv. Carbohydr. Chem. Biochem. 1975, 31, 241.

6. Grant, G. T.; McNab, C.; Rees, D. A.; Skerrett, R. F. Chem. Commun. 1969, 805. 
7. Mammen, M.; Choi, S.-K.; Whitesides, G. M. Angew. Chem. Int. Ed. 1998, 37, 2745.

8. Geyer A.; Gege, C.; Schmidt, R. R. Angew. Chem. Int. Ed. 1999, 38, 1466.

9. Mazzini, M. N.; Cerezo, A. S. J. Sci. Food Agric. 1979, 30, 881.

10. Buckeridge, M. S.; Grant Reid, J. S. Ciencia e Cultura 1996, 48, 153.

11. Bewley, J. D.; Black, M. Seeds: physiology of development and germination. $2^{\text {nd }}$ Edn.; Plenum Press: New York, 1994; pp 1-445.

12. Kang, E-C., Akiyoshi, K.; Sunamoto, J. Int. J. Macromol. Biol. 1994, 16, 348.

13. Acebes, J. L.; Lorences, E. P. ; Revilla, G.; Zarra, I., Physiol. Plantarum 1993, 89, 417.

14. Hanessian, S.; Simard, M.; Roelens, S., J. Am. Chem. Soc. 1995, 117, 7630.

15. Flores, M. L.; Stortz, C. A.; Cerezo, A. S. Int. J. Biol. Macromol. 2000, 27, 21.

16. Estevez, J. M.; Ciancia, M.; Cerezo, A. S., unpublished results.

17. Lechat, H.; Amat, M.; Mazoyen, F.; Buleon, H.; Lahaye, M. J. Phycol. 2000, 36, 891.

18. Cardoso, S. M.; Silva, A. M. S.; Coimbra, M. A. Carbohydr. Res. 2002, 337, 917.

19. Churms, S. C.; Merrifield, E. H.; Stephen, A. M.; Walwyn, D. R.; Polson, A.; van der Merwe, K. J.; Spies, H. S. C.; Costa, N. Carbohydr. Res. 1983, 113, 339.

20. Zawadski-Baggio, S. F.; Sierakowski, M.-R.; Corrêa, J. B. C.; Reicher, F. Carbohydr. Res. 1992, 233, 265.

21. Petkowicz, C. L. O.; Sierakowski, M. R.; Ganter, J. L. M. S.; Reicher, F. Phytochemistry 1998, 49, 737.

22. Hervé du Penhoat, C.; Michon, V.; Goldberg, R. Carbohydr. Res. 1987, 165, 31.

23. Capek, P.; Toman, R.; Kardošová, A.; Rosík, J. Carbohydr. Res. 1983, 117, 107.

24. Hirst, E. L.; Jones, J. K. N.; Walder, W. O. J. Chem. Soc. 1947, 1225.

25. Wood, P. J.; Siddiqui, I. R. Carbohydr. Res. 1972, 22, 212.

26. Clarke, A. E.; Anderson, R. L.; Stone, B. A. Phytochemistry 1979, 18, 521.

27. Carpita, N. C.; Gibeaut, D. M. Plant J. 1993, 3, 1.

28. Dubois, M.; Gilles, K.A.; Hamilton, J. K.; Rebers, P. A.; Smith, F. Anal. Chem. 1956, 28, 350 .

29. Lowry, O. H.; Rosebrough, N. J.; Farr, A. L.; Randall, R. J. J. Biol. Chem. 1951, 193, 265.

30. Park, J. T.; Johnson, M. J. J. Biol. Chem. 1949, 181, 149.

31. Filizetti-Cozzi, T. M. C. C.; Carpita, N. C. Anal. Biochem. 1991, 197, 157.

32. Hakomori, S.-I. J. Biochem. (Tokyo) 1964, 55, 205. 